\title{
Prevalence and associated factors of myopia among high school students in Gondar town, northwest Ethiopia, 2016
}

This article was published in the following Dove Press journal:

Clinical Optometry

23 December 2016

Number of times this article has been viewed

\author{
Gizachew Tilahun Belete' \\ Dereje Hayilu Anbesse' \\ Adino Tesfahun Tsegaye ${ }^{2}$ \\ Mohammed Seid Hussen' \\ 'Department of Optometry, \\ ${ }^{2}$ Department of Biostatistics and \\ Epidemiology, Institute of Public \\ Health, College of Medicine and \\ Health Science, University of Gondar, \\ Gondar, Ethiopia
}

Introduction: Myopia is an important cause of correctable visual impairment and preventable blindness worldwide. Prevalence rates are approximately $20 \%-35 \%$ among the older teenage population globally. It has a medical burden of pathologic complications such as maculopathy and glaucomatous optic neuropathy. High school students experience high-performance and study pressures in the preparation for the final national examination. As a result they are exposed to excessive near work and indoor activities. They are also ignored for regular screening.

Objective: To determine the prevalence and associated factors of myopia among high school students in Gondar town, Ethiopia.

Methods: An institution-based cross-sectional study was conducted on 498 high school students with systematic random sampling method from April 18 to April 29, 2016, in three full-cycle high schools (9th-12th grades). A standardized structured questionnaire, Snellen acuity chart, pinhole, retinoscope, trial case lenses, pen torch, and direct ophthalmoscope were used to collect data. Results: A total of 495 study participants were included, and they had a mean age of $17.48 \pm 1.59$ years. The prevalence of myopia was $11.9 \%$ (95\% confidence interval [CI]: 10.2, 17.9). Family history of myopia (adjusted odds ratio $[\mathrm{AOR}]=8.08$ [95\% CI: 4.30, 15.16]), school being private (AOR=2.88 [95\% CI: 1.02, 8.11]), longer time spent for near work (AOR=2.89 [95\% CI: 1.12, 7.43]), longer time spent partaking in indoor activities ( $\mathrm{AOR}=4.32$ [95\% CI: 1.69, 10.99]), shorter near working distance (AOR=3.06 [95\% CI: 1.33, 7.06]), lack of outdoor sport activities (AOR=2.27 [95\% CI: $1.05,4.90])$, use of visual display units (AOR=2.81 [95\% CI: 1.30, 6.10]), and abnormal ocular findings (AOR=6.69 [CI: 3.43, 13.03]) were found to be independently associated with myopia. Conclusion: The prevalence of myopia was $11.9 \%$. Family history for myopia, school being private, longer time spent partaking in indoor activities, shorter working distance, lack of outdoor sport activities, use of visual display units, and presence of abnormal ocular findings were positively associated with myopia.

Keywords: myopia, high school students, Gondar town, Ethiopia

\section{Introduction}

Myopia is defined as nearsightedness caused by an incongruity between the power of the optical elements of the eye and its axial length. The object image is projected in front of the retina, and corrective lenses are necessary to displace this image backward, thus producing a clear retinal image. ${ }^{1}$ It is an important cause of correctable visual impairment and preventable blindness worldwide. The main clinical presentations are reduction of distance and/or near vision, reduction of color vision and contrast sensitivity, constriction of visual field, fear of light, and loss of vision. ${ }^{2,3}$ Almost all patients with myopia can have good vision if early and appropriate correction has been given. ${ }^{4}$
Correspondence: Gizachew Tilahun Belete

Department of Optometry, College of Medicine and Health Science, University of Gondar, Gondar 196, Ethiopia Tel +25 I 9 I 2684323

Email gizachewtilahun I@gmail.com 
Myopia has a global distribution with a widely varying incidence and prevalence. It is more common in Asian countries but relatively less common in Europe and North American countries. ${ }^{5}$ Its prevalence and distribution in Africa is lower than both Asian and European countries. ${ }^{5,6}$ The prevalence reaches $20 \%-25 \%$ in school age and young adults and $25 \%-35 \%$ among the mid- to late teenage population in the world. ${ }^{2}$ The prevalence of myopia declines somewhat in the population over age 45 years, reaching about $20 \%$ in 65 -year-olds, decreasing to as low as $14 \%$ of persons in the seventies. ${ }^{2,7}$ On the other hand, the prevalence of myopia in the late teenage population becomes even higher in Asian countries, which extends up to $80 \%$ in China. ${ }^{5,8}$

Myopia and its pathological complication have reached epidemic proportions and become a large public health problem in certain parts of the world, especially in East Asian countries. ${ }^{79}$ The medical burden of myopia includes pathologic complications such as maculopathy and glaucomatous optic neuropathy in association with high myopia and it becomes one of the leading causes of blindness and visual impairment. ${ }^{3}$ Others such as choroidal neovascularization and cataract could also impair vision-related quality of life and increase difficulty in performing vision-related tasks. ${ }^{5}$

It has considerable burden on individual and society that can have negative impact on career choice, ocular health, and sometimes self-esteem. Students constitute a particularly vulnerable group, where myopia may have a great impact on learning capability and educational potential, as well as economic cost to the family and government. ${ }^{10}$

The causes of myopia are unclear, although evidence supports both genetic and environmental components; it has been associated with socioeconomic status, level and length of education, parental myopia, exposure to near work, and level of intelligence. ${ }^{9-12}$ Even though, they are not major factors, level of lighting, ${ }^{13}$ stress, pharmacological agents, and amount of time spent for indoor activities have an effect on the development of myopia. ${ }^{14}$

Although myopia is a common public vision problem, except a few community- and school-based studies on preschool and schoolchildren, there are limited information among high school students particularly in the study area. ${ }^{15}$

According to different studies done across the world, the prevalence of myopia has a discrepancy and varies widely.

Different cross-sectional studies in the world showed that the prevalence of myopia ranges from $2.9 \%$ to $96.54 \%{ }^{3,8,16-24}$

The major associated factors revealed through different literature are sociodemographic characteristics, such as sex, with being female found to increase risk, ${ }^{3,4,6,11,18,24}$ and age, ${ }^{25}$ but religion had not been found to have an association with myopia. ${ }^{26}$ Environmental and educational factors including close working distance ${ }^{3,21}$ and longer time spent for near work had a significant association with myopia. ${ }^{27}$ Family history of myopia is also a determinant factor to have myopia and the probability becomes higher when both parents had myopia. $^{22,27,28}$

Therefore, high school students are at high performance and study pressure in the preparation for the final national examination that may lead to the development of myopia. Most of them spent their time reading at near, which in turn was a major factor for myopia development and progression even after distance correction. These groups of students are also ignored for regular screening and studies were not well revealed. In addition, myopia is of high public health importance in Ethiopia with regard to preventing visual impairment. This reason is true in particular if one considers that the young myopic generation of today can eventually develop age-dependent myopia-associated complications such as myopic maculopathy and myopic glaucomatous optic neuropathy, when the myopic individuals grow older.

\section{Materials and methods}

Institution-based cross-sectional study was conducted in Gondar town, northwest Ethiopia, between April 18 and April 29, 2016. Data obtained from Gondar town administration statistical office indicated that Gondar city is located in North Gondar zone, which is situated $748 \mathrm{~km}$ from the capital city, Addis Ababa. According to the 2007 National Census, it has a population of 207,044 divided in 21 kebeles (the smallest unit of administration) and 10 subcities and approximately the town hosts about 53,725 households. ${ }^{29}$ According to the Gondar town educational office there are 14 high schools ( 9 government and 5 private) that hosts 18,122 students. Out of these schools, eight of them are 9th-12th grades (full cycle) and the rest six are 9th-10th grades. The data were collected from high school students at Azezo, Debre Selam, and Shenta high schools. There is one government hospital - University of Gondar tertiary eye care and training center and two private clinics, which provide different specialty eye care services and training of eye care professionals such as optometrists and ophthalmologists.

\section{Source population and sample size}

Out of all high school students, 498 students were selected for the study. However, students who had recent history of ocular trauma and active ocular infection especially on the cornea and crystalline lens were excluded from the study. 


\section{Sample size determination}

\section{Sample size for objective one}

Sample size was determined by single proportion formula taken from similar study in Tanzania: ${ }^{11}$

$$
n=\frac{\left(Z_{a / 2}\right)^{2} P(1-P)}{d^{2}}
$$

where $n$, sample size; $Z$, value of $z$ statistic at $95 \%$ confidence interval $(\mathrm{CI})=1.96 ; P$, proportion of myopia from similar study conducted in Mwanza City town, Tanzania, was 5.59\% (0.0559), $1-P=0.9441, d$, margin of error $3 \%=0.03$, and the sample size was 226 .

\section{Sample size for objective two}

By taking a similar study conducted in Mwanza City town, Tanzania, parental/familial myopia was considered as main consistent factor for myopia and used for sample size determination. By using EPI INFO version 7 computer software and considering $95 \% \mathrm{CI}, 80 \%$ power, by considering the ratio of those who have no familial myopia to those who have familial myopia as $1: 1,37 \%$ of unexposed develop the case, and the computer-generated sample was 148. Sample size of objective one was selected because it was larger and adequate to meet both objectives. Therefore, by considering $10 \%$ to nonresponse rate and 2 for a design effect during the sampling procedure, the final required sample size was 498 .

\section{Sampling technique and procedures}

Multistage sampling technique was used during the sampling process. To ensure representativeness, sample was taken from about $37.5 \%$ of the total full-cycle high schools. As shown in Figure 1 first, 3 schools out of 8 full-cycle high schools were selected using simple random sampling method after a list of schools obtained from the Gondar town educational office. In the three selected schools, there were a total of 5642 students. Then systematic random sampling method

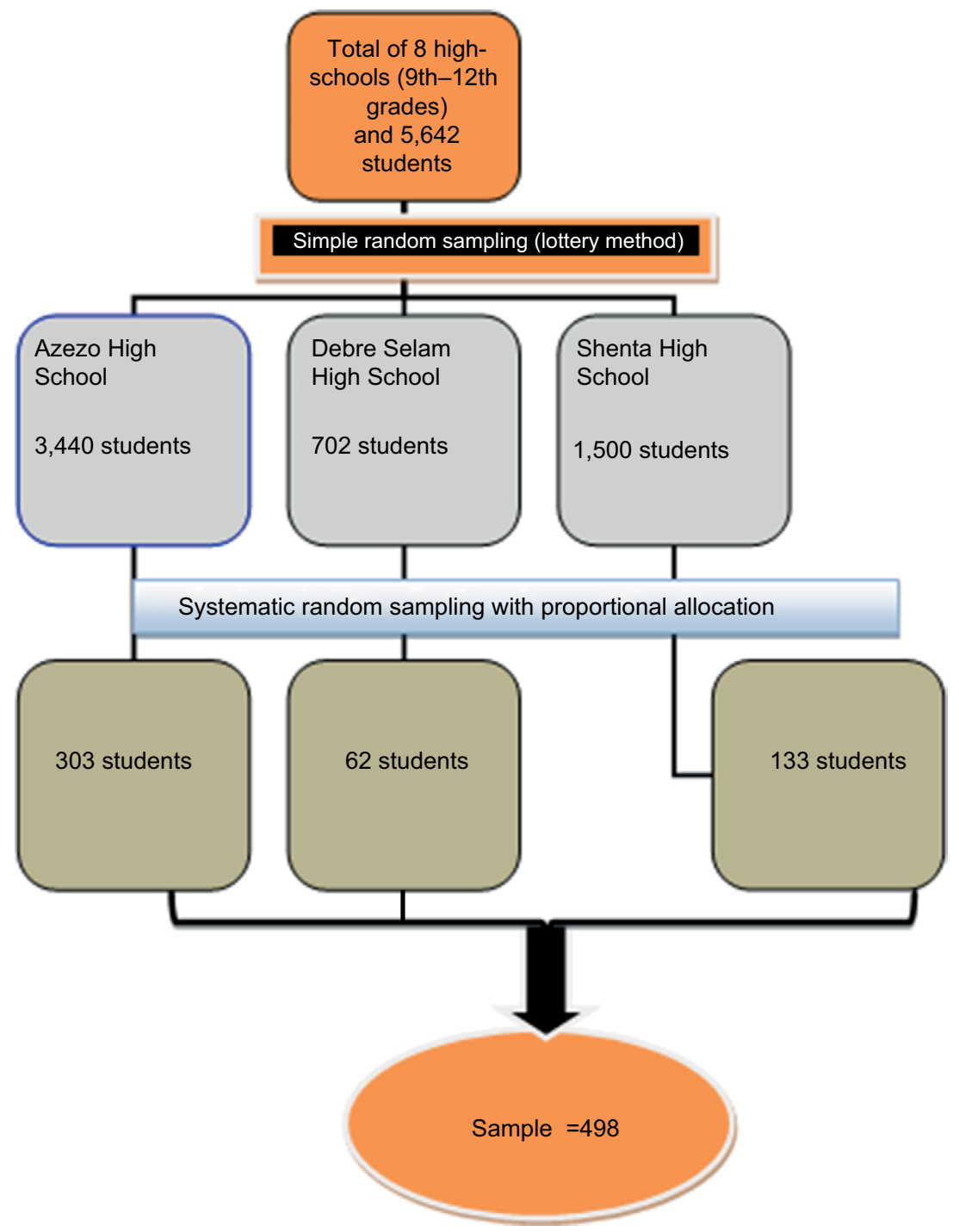

Figure I Schematic presentation of sampling procedure. 
was used to select participating students with proportional allocation by a sampling fraction of 11 .

\section{Operational definitions}

- Myopia: Defined as spherical equivalent refractive error $(\mathrm{SER}=$ sphere $+1 / 2$ cylinder $)$ of $-0.50 \mathrm{D}$ or more in either eye. Participants with anisomyopia were categorized based on the more myopic eye. On the basis of the American Academy of Optometry myopia $<-3.00 \mathrm{D}$ is low myopia, $-3.00 \mathrm{D}$ to $-6.00 \mathrm{D}$ is medium, and $>-6.00$ $\mathrm{D}$ is high myopia.

- Familial myopia: The presence of any degree of myopia in first-degree relatives (father, mother, brothers, and sisters) diagnosed by eye care professionals during examination.

- Working distance: The habitual distance at which a person adapts to do near tasks and $33 \mathrm{~cm}$ is considered as the average/normal value. Any working distance $<25 \mathrm{~cm}$ is considered as close working distance.

- Ocular abnormality: Any ocular disorder (such as keratoconus and other corneal ectasias, corneal degenerations and dystrophies, cataract, lens subluxation/dislocation, and retinal disorders) that can induce myopia during its course or as a consequence of the disease process as determined by ocular examination.

\section{Data collection procedures (instrument, personnel)}

The standardized structured questionnaire was used to collect data regarding sociodemographic, family-related, environmental, and educational information. Data recording format and checklist were used for near reading, refraction, and ocular examination. Six trained optometrists were participated in data collection. The selected students were interviewed and ocular examination was carried out at each specific school by using Snellen acuity test chart, pinhole, retinoscope, trial case lenses, hand-held portable slit lamp, and direct ophthalmoscope. The examination room was semi-dark during refraction with a local available blue-black curtain. After adjusting the room illumination visual acuity was taken for all students. Visual acuity of worse than 6/9 was taken as cutoff point and pinhole was performed for any visual acuity improvement, then noncycloplegic objective refraction was carried out by a senior experienced optometrist to determine myopia. However, cycloplegic refraction was done for suspected pseudo-myopes to confirm their myopia. The principal investigator decided when there is a discrepancy in diagnosis of myopia. Myopia was defined as $\mathrm{SER}=$ sphere $+1 / 2$ cylinder of $-0.50 \mathrm{D}$ or more in either eye. Participants with anisomyopia were categorized based on the more myopic eye.

\section{Data processing and analysis}

After coding, the data were entered into EpiData 3.1 then exported and analyzed by using SPSS version 20. Proportions and summary statistics were performed. Bivariable and multivariable logistic regressions were used to determine the associated factors. The variables that were found with $p<0.2$ at bivariable logistic regression were entered to multivariable analysis and those variables with $p$-value $<0.05$ were considered statistically significant.

\section{Ethical consideration}

Ethical clearance was obtained from the ethical review board of the University of Gondar. Each participating school was visited a week before the data collection day, and permission to conduct the study was also obtained from the schools. A written informed consent form was given to each of the students aged $<18$ years to be taken to their parents or guardians the day before data collection. Students aged $<18$ years were only recruited if their parents or guardians gave assent and signed the consent forms, and were willing for the students to take part in the study. All study participants aged $\geq 18$ years and above provided their own written informed consent. Confidentiality of their information was assured through not writing their name, interviewing participants privately, and by keeping the collected information locked (not to make accessible for others other than the research team). Participants who were found to have myopia and any other ocular disorders were referred to University of Gondar Tertiary Eye and Training Center and underwent full ocular examination.

\section{Results \\ Sociodemographic characteristics of the study participants}

A total of 495 study participants were included in the study with a response rate of $99.4 \%$. Among them, 257 (51.9\%) were females. The mean age of the study participants was $17.48 \pm 1.59$ years (range 15-22 years) and the mean age at start of formal school was $6.49+1.35$ years (range 3-9 years). Most of the study participants were Ethiopian Orthodox (type of Christianity), 425 (86\%). One-third of the study participants' parental educational status was found to be able to read and write, 134 (27.1\%) (Table 1). Among the study participants, 278 (56.2\%) were of 9 th and 10th grades.

\section{Magnitude of myopia}

Out of 495 study participants, 59 (11.9\%) (95\% CI: 10.2, 17.9) were myopic and among them $32(54.2 \%)$ had familial myopia. In more than half of the students with familial 
Table I Sociodemographic characteristics of study participants among high-school students in Gondar town, northwest Ethiopia, 2016

\begin{tabular}{ll}
\hline Variables & Frequency (\%) \\
\hline Age category & $150(30.3)$ \\
15-17 years & $218(44.0)$ \\
18-19 years & $127(25.7)$ \\
20-22 years & \\
Age at start of formal school & $244(49.3)$ \\
3-6 years & $152(30.7)$ \\
7 years & $99(20.0)$ \\
$8-9$ years & \\
Sex & $257(51.9)$ \\
Female & $238(48.9)$ \\
Male & \\
School type & $432(87.3)$ \\
Government & $63(12.7)$ \\
Private & \\
Religion & $425(85.9)$ \\
Ethiopian orthodox & $44(8.9)$ \\
Muslim & $16(3.2)$ \\
Protestant & $10(2.0)$ \\
Catholic & \\
Parental education status & $95(19.2)$ \\
Unable to write and read & $134(27.1)$ \\
Able to read and write & $58(11.7)$ \\
Primary school & $96(19.4)$ \\
Secondary school & $112(22.6)$ \\
College/university &
\end{tabular}

myopia, 17 (53.1\%) had $>1$ family with myopia. On the basis of the degree of myopia, $40(67.8 \%)$ had low degree of myopia. Among the study participants, 68 (13.7\%) had ocular abnormalities of whom $26(44.0 \%)$ had myopia (Table 2$)$.

\section{Factors associated with myopia}

As a result, those study participants who had positive family history of myopia were 8 times more likely to develop myopia as compared to those who had no family history of myopia (adjusted odds ratio $[\mathrm{AOR}]=8.08$ [95\% CI: 4.30, 15.16]). Those students who were using a working distance of $<33 \mathrm{~cm}$ were 3 times more likely to develop myopia as compared to those who used a working distance of $>60 \mathrm{~cm}$ $(\mathrm{AOR}=3.06$ [95\% CI: 1.33, 7.06]). The study participants who spent 9-11 hours per day for near work were 2.89 times more likely to develop myopia as compared to those who spent $<3$ hours per day (AOR=2.89 [95\% CI: 1.12, 7.43]). Students who spent 9-11 hours for indoor activities per day were also 4.32 times more likely to develop myopia as compared to those who spent $<3$ hours per day $(\mathrm{AOR}=4.32$ [95\% CI: 1.69, 10.99]). Those study participants who did not spend time for outdoor sport activities were 2.27 times more likely to develop myopia as compared to those who spent time in outdoor sport activities $(\mathrm{AOR}=2.27$ [95\% CI:
Table 2 Proportion of myopia, familial myopia, and ocular abnormalities among study participants in Gondar town, northwest Ethiopia, 2016

\begin{tabular}{ll}
\hline Variables & Frequency (\%) \\
\hline Myopia (n=495) & $59(11.9)$ \\
Yes & $436(88.1)$ \\
No & \\
Degree of myopia (n=495) & $40(8.1)$ \\
Low & $15(3.0)$ \\
Moderate & $4(0.81)$ \\
High & \\
Ocular abnormality $(\mathbf{n}=495)$ & $68(86.3)$ \\
Yes & $427(13.7)$ \\
No & \\
Familial myopia (n=495) & $411(83.0)$ \\
No family history & $49(9.9)$ \\
History in one family member & $35(7.1)$ \\
History in more than one family member &
\end{tabular}

$1.05,4.90])$. Students who used visual display units (VDUs) were 2.8 times more likely to develop myopia as compared to the nonusers $(\mathrm{AOR}=2.81$ [95\% CI: 1.30, 6.10]). Study participants who were in private school were 2.88 times at risk of developing myopia as compared to those who attend government schools (AOR=2.88 [CI: 1.02, 8.11]). Students who had ocular abnormality were 6.70 times more likely to develop myopia as compared to those who had not abnormal ocular findings $(\mathrm{AOR}=6.69$ [CI: 3.43, 13.03]) (Table 3).

\section{Discussion}

In this study the prevalence of myopia was 59 (11.9\%) (95\% CI: 10.2, 17.9). This finding is consistent with other studies conducted in Poland (13.3\%) ${ }^{17}$ and Amman city (17.6\%). ${ }^{22}$ However, compared with studies done in Tanzania $(5.59 \%)$, Ghana (4.5\%), and Nigeria (2.9\%), ${ }^{6,11,24}$ this finding is larger. The possible explanation could be that the proportion of female participants to male in this study was higher. As reviewed earlier, females are more susceptible than males to myopia. Therefore, the prevalence in this study is higher as compared with the Nigeria, Ghana, and Tanzania studies. On the other hand, the prevalence of myopia in this study is relatively lower than other studies done in America (53.4\%), Israel (20.3\%), and India (19.1\%). ${ }^{4,16,19}$ In addition, in studies done in China (80\%-95\%), Hong Kong (85\%-88\%), and South Korea $(96.54 \%),{ }^{3,9,20}$ the prevalence of myopia is very high as compared with this study. This difference might be because of the variation in race between the study participants and Asian descent. Most Asian nations were more myopic as a result of complex genetic trait and environmental factors responsible for myopia; ${ }^{2}$ on the other hand, because of advancement of technology in developed nations, students were subjected for excessive near tasks. 
Table 3 Factors associated with myopia of study participants among high-school students, Gondar town, northwest Ethiopia, 2016

\begin{tabular}{|c|c|c|c|c|}
\hline \multirow[t]{2}{*}{ Variables } & \multicolumn{2}{|c|}{ Myopia } & \multirow{2}{*}{$\begin{array}{l}\text { Crude odds } \\
\text { ratio }(95 \% \mathrm{Cl})\end{array}$} & \multirow{2}{*}{$\begin{array}{l}\text { Adjusted odds } \\
\text { ratio }(95 \% \mathrm{Cl})\end{array}$} \\
\hline & Yes & No & & \\
\hline \multicolumn{5}{|l|}{ Sex* } \\
\hline Male & 16 & 222 & 1.00 & \\
\hline Female & 43 & 214 & $2.79(1.52,5.10)$ & \\
\hline \multicolumn{5}{|l|}{ School type } \\
\hline Government & 46 & 386 & 1.00 & 1.00 \\
\hline Private & 13 & 50 & $2.18(1.10,4.31)$ & $2.88(\mathrm{I} .02,8.1 \mathrm{I})^{* *}$ \\
\hline \multicolumn{5}{|c|}{ Duration of schooling* } \\
\hline $9-10$ years & 13 & 148 & 1.00 & \\
\hline $11-12$ years & 34 & 215 & $\mathrm{I} .80(0.91,3.52)$ & \\
\hline$>12$ years & 12 & 73 & I.87 $(0.83,4.30)$ & \\
\hline \multicolumn{5}{|l|}{ Family history } \\
\hline No & 27 & 384 & 1.00 & 1.00 \\
\hline Yes & 32 & 52 & I $3.43(6.22,28)$ & $8.08(4.30,15.16)^{* * *}$ \\
\hline \multicolumn{5}{|c|}{ Time spent in indoor activities } \\
\hline$<3$ hours/day & 12 & 145 & 1.00 & 1.00 \\
\hline 3-8 hours/day & 12 & 160 & $0.90(0.40,2.08)$ & $0.9 \mathrm{I}(0.33,2.5 \mathrm{I})$ \\
\hline 9-II hours/day & 24 & 88 & $3.30(1.57,6.92)$ & $4.31(1.69,10.99)^{* *}$ \\
\hline$>$ II hours/day & 11 & 43 & $09(1.27,7.50)$ & $2.43(0.75,7.84)$ \\
\hline \multicolumn{5}{|c|}{ Ocular abnormalities } \\
\hline No & 33 & 394 & 1.00 & 1.00 \\
\hline Yes & 26 & 42 & $7.40(4.03,13.52)$ & $6.69(3.43,13.03)^{* * *}$ \\
\hline \multicolumn{5}{|c|}{ Time spent for near work } \\
\hline$<3$ hours/day & 10 & 164 & 1.00 & 1.00 \\
\hline 3-8 hours/day & 13 & 165 & $1.29(0.55,3.03$ & $0.85(0.32,2.22)$ \\
\hline 9-II hours/day & 21 & 59 & $5.84(2.60,13.11)$ & $2.89(1.12,7.43)^{* *}$ \\
\hline$>1 \mathrm{I}$ hours/day & 15 & 48 & $5.12(2.16,12.14)$ & $1.98(0.66,5.98)$ \\
\hline \multicolumn{5}{|c|}{ Time spent in outdoor activities* } \\
\hline$<3$ hours/day & 23 & 128 & $0.88(0.39,1.98)$ & \\
\hline $3-8$ hours/day & 13 & 139 & $0.46(0.191,11)$ & \\
\hline 9-II hours/day & 13 & 120 & $0.53(0.22,1.29)$ & \\
\hline$>$ II hours/day & 10 & 49 & 1.00 & \\
\hline \multicolumn{5}{|c|}{ Outdoor sport activities } \\
\hline No & 45 & 234 & $2.77(1.48,5.20)$ & $2.27(1.05,4.90)^{* *}$ \\
\hline Yes & 14 & 202 & 1.00 & 1.00 \\
\hline \multicolumn{5}{|c|}{ Working distance } \\
\hline$<33 \mathrm{~cm}$ & 32 & 72 & $5.23(2.59,10.56)$ & $3.06(1.33,7.06)^{* *}$ \\
\hline $33-60 \mathrm{~cm}$ & 14 & 211 & $0.78(0.36,1.70)$ & $0.49(0.18,1.20)$ \\
\hline$>60 \mathrm{~cm}$ & 13 & 153 & 1.00 & 1.00 \\
\hline \multicolumn{5}{|c|}{ Active rest during studying* } \\
\hline No & 22 & 116 & $1.64(0.30,2.90)$ & \\
\hline Yes & 37 & 320 & 1.00 & \\
\hline \multicolumn{5}{|c|}{ Type of illumination* } \\
\hline Candle & 12 & 54 & $2.73(1.19,6.26)$ & \\
\hline Table light & 13 & 68 & $2.35(1.05,5.25)$ & \\
\hline Dim light & 20 & 142 & $73(0.84,3.55)$ & \\
\hline Fluorescent/lamp & 14 & 172 & 1.00 & \\
\hline \multicolumn{5}{|c|}{ Visual display unit use } \\
\hline No & 17 & 191 & 1.00 & 1.00 \\
\hline Yes & 42 & 245 & $1.93(1.06,3.49)$ & $2.81(1.96,6.10)^{* *}$ \\
\hline
\end{tabular}

Notes: *Nonsignificant, **p-value $<0.05, * * * p$-value $<0.001$.

Abbreviation: $\mathrm{Cl}$, confidence interval.

The study participants who had positive family history of myopia were 8 times more likely to develop myopia as compared to those who had no family history of myopia. Studies conducted in Amman city, Beijing, and Greece agree with the finding of this study. ${ }^{22,27,28}$ This is because of that myopia had high genetic basis as suggested that juvenileonset myopia may be inherited as a complex trait involving genetic and environmental factors and it is true that myopia should cluster in families.

Those study participants who use short working distance of $<33 \mathrm{~cm}$ were 3 times more likely to develop myopia as compared to those who used a working distance of $>60 \mathrm{~cm}$. This result is supported by other studies done in Norway, ${ }^{30}$ China, ${ }^{3}$ and Vietnam. ${ }^{21}$ This might be because of the fact that persistent short working distance leads to peripheral blur and inherent ciliary spasm that could cause myopia gradually.

The study participants who spent 9-11 hours per day for near work were 2.89 times more likely to develop myopia as compared to those who spent $<3$ hours per day. This study is in line with other studies done in Beijing, China. ${ }^{27}$ This might be as a result of that subjects who spent more time for near work are at higher risk of inherent ciliary spasm that in turn will lead to defocused retinal image and myopia development.

In this study, students who spent 9-11 hours for indoor activities per day were also 4.32 times more likely to develop myopia as compared to those who spent $<3$ hours per day. This result is supported by other studies in Australia and Taiwan. ${ }^{30,31}$ This may be as a result of the illumination condition during indoor activities being different from natural light that prevents the release of dopamine. In addition, the distance where activities are performed while performing indoor activities is short as compared to outdoor activities.

Those study participants who did not spend time for outdoor sport activities were 2.27 times more likely to develop myopia as compared to those who spent time in outdoor sport activities. It is in agreement with a study in Ohio State University, America. ${ }^{13}$ It may be explained in a way that, by nature most of the outdoor sport activities do not need any near focusing and accommodation and performed under natural illumination in contrast to those who did not spend time in outdoor sport activities. It is also suggested that natural light and outdoor sport activities might prevent myopia by increasing the release of dopamine from the retina, because dopamine has been known to be an inhibitor of axial elongation. ${ }^{27}$

Students who used VDUs were 2.8 times more likely to develop myopia as compared to nonusers. A study conducted in Beijing childhood study center ${ }^{27}$ also confirmed the effect of VDUs on myopia development. The reason behind this may be the constant stimulation of accommodation and pupillary dilation that leads to retinal image defocus. Study 
participants who were in private school were 2.88 times at risk of developing myopia as compared to those who attend government schools, and this finding agrees with a study conducted in China. ${ }^{27}$ The possible reason for this may be educational facilities such as computers and books and that the time spent in class in private schools was higher as compared to government schools.

Students who had ocular abnormality were 6.70 times more likely to develop myopia as compared to those who had no abnormal ocular finding. This result is similar to the study done in Singapore. ${ }^{7}$ The most likely reason to this association is that different ocular abnormalities can disturb the optical integrity of the eye, either the curvature or the axial length.

\section{Conclusion}

The prevalence of myopia among high-school students in Gondar town was $11.9 \%$. Positive family history for myopia, school being private, longer time spent for indoor activities, short working distance, lack of outdoor sport activities, use of VDUs, and presence of abnormal ocular findings were positively associated with myopia.

\section{Disclosure}

The authors report no conflicts of interest in this work.

\section{References}

1. Saw SM, Wu HM, Seet B, et al. Academic achievement, close up work parameters, and myopia in Singapore military conscripts. $\mathrm{Br} J$ Ophthalmol. 2001;85(7):855-860.

2. Goss DA, Grosvenor TP, Keller JT, Marsh-Tootle W, Norton TT, Zadnik K. Optometric Clinical Practice Guideline Care of the Patient with Myopia. St. Louis, MO: American Optometric Association; 1997:243.

3. Wu LJ, You QS, Duan JL, et al. Prevalence and associated factors of myopia in high-school students in Beijing. PLoS One. 2015;10(3):e0120764.

4. Bar Dayan Y, Levin A, Morad Y, et al. The changing prevalence of myopia in young adults: a 13-year series of population-based prevalence surveys. Invest Ophthalmol Vis Sci. 2005;46(8):2760-2765.

5. Pan CW, Ramamurthy D, Saw SM. Worldwide prevalence and risk factors for myopia. Ophthalmic Physiol Opt. 2012;32(1):3-16.

6. Nakua E, Otupiri E, Owusu-Dabo E, Dzomeku V, Otu-Danquah K, Anderson M. Prevalence of refractive errors among junior high school students in the Ejisu Juaben municipality of Ghana. J Sci Technol (Ghana). 2015;35(1):52-62.

7. Saw SM, Gazzard G, Shih-Yen EC, Chua WH. Myopia and associated pathological complications. Ophthalmic Physiol Opt. 2005;25(5):381-391

8. Congdon N, Wang Y, Song Y, et al. Visual disability, visual function, and myopia among rural Chinese secondary school children: the Xichang Pediatric Refractive Error Study (X-PRES)—report 1. Invest Ophthalmol Visual Sci. 2008;49(7):2888-2894.

9. Lam CSY, Goldschmidt E, Edwards MH. Prevalence of myopia in local and international schools in Hong Kong. Optom Vis Sci. 2004;81(5):317-322

10. Woldeyes A, Misganaw C, kassa N. Prevalence and factors associated with refractive error among primary school children in Addis Ababa, Ethiopia. Int J Med Health Sci Res. 2014;1(9):92-104.
11. Wedner S, Ross D, Todd J, Anemona A, Balira R, Foster A. Myopia in secondary school students in Mwanza City, Tanzania: the need for a national screening programme. Br J Ophthalmol. 2002;86(11):1200-1206.

12. Wensor M, McCarty CA, Taylor HR. Prevalence and risk factors of myopia in Victoria, Australia. Arch Ophthalmol. 1999;117(5):658-663.

13. Jones LA, Sinnott LT, Mutti DO, Mitchell GL, Moeschberger ML, Zadnik K. Parental history of myopia, sports and outdoor activities, and future myopia. Invest Ophthalmol Vis Sci. 2007;48(8): 3524-3532.

14. Sherwin JC, Reacher MH, Keogh RH, Khawaja AP, Mackey DA, Foster PJ. The association between time spent outdoors and myopia in children and adolescents: a systematic review and meta-analysis. Ophthalmology. 2012;119(10):2141-2151.

15. Yared AW, Belaynew WT, Destaye S, Ayanaw T, Zelalem E. Prevalence of refractive errors among school children in Gondar town, northwest Ethiopia. Middle East Afr J Ophthalmol. 2012;19(4):372-376.

16. Loman J, Quinn GE, Kamoun L, Ying GS, Maguire MG, Hudesman D, Stone RA. Darkness and near work: myopia and its progression in third-year law students. Ophthalmology. 2002;109(5):1032-1038.

17. Czepita D, Żejmo M, Mojsa A. Prevalence of myopia and hyperopia in a population of Polish schoolchildren. Ophthalmic Physiol Opt. 2007; 27(1):60-65

18. Sun J, Zhou J, Zhao P, et al. High prevalence of myopia and high myopia in 5060 Chinese university students in Shanghai. Invest Ophthalmol Vis Sci. 2012;53(12):7504-7509.

19. Joseph N, Nelliyanil M, Rekha T, Rai S, Kotian SM. Proportion of refractive error and its associated factors among high school students in South India. Br J Med Med Res. 2015;11(11):1-9.

20. Jung SK, Lee JH, Kakizaki H, Jee D. Prevalence of myopia and its association with body stature and educational level in 19-year-old male conscripts in Seoul, South Korea. Invest Ophthalmol Vis Sci. 2012;53(9):5579-5583.

21. Paudel P, Ramson P, Naduvilath T, Wilson D, Phuong HT, Ho SM, Giap NV. Prevalence of vision impairment and refractive error in school children in Ba Ria-Vung Tau province, Vietnam. Clin Exp Ophthalmol. 2014;42(3):217-226.

22. Khader YS, Batayha WQ, Abdul-Aziz SM, Al-Shiekh Khalil MI. Prevalence and risk indicators of myopia among schoolchildren in Amman, Jordan. East Mediterr Health J. 2006;12(3-4):434-439.

23. Ip JM, Saw SM, Rose KA, Morgan IG, Kifley A, Wang JJ, Mitchell P. Role of near work in myopia: findings in a sample of Australian school children. Invest Ophthalmol Vis Sci. 2008;49(7):2903-2910.

24. Balarabe AH, Adamu I, Abubakar A. Vision screening to detect refractive errors in three selected secondary schools in Birnin Kebbi, North West, Nigeria. Sahel Med J. 2015;18(2):61-65.

25. Lin L, ShihY, Hsiao C, Chen C. Prevalence of myopia in Taiwanese schoolchildren: 1983 to 2000. Ann-Acad Med Singapore. 2004;33(1):27-33.

26. Lim WY, Saw SM, Singh MK, Au Eong KG. Utility values and myopia in medical students in Singapore. Clin Exp Ophthalmol. 2005; 33(6):598-603.

27. You QS, Wu LJ, Duan JL, et al. Factors associated with myopia in school children in China: the Beijing childhood eye study. PLoS One. 2012;7(12):e52668.

28. Konstantopoulos A, Yadegarfar G, Elgohary M. Near work, education, family history, and myopia in Greek conscripts. Eye (Lond). 2008;22(4):542-546.

29. United Nations Population Fund (UNFPA). Summary and Statistical Report of the 2007 Population and Housing Census: Population Size by Age and Sex. Adida Ababa, Ethiopia: United Nations Population Fund (UNFPA); 2008.

30. French AN, Morgan IG, Mitchell P, Rose KA. Risk factors for incident myopia in Australian schoolchildren: the Sydney adolescent vascular and eye study. Ophthalmology. 2013;120(10):2100-2108.

31. Lee YY, Lo CT, Sheu SJ, Lin JL. What factors are associated with myopia in young adults? A survey study in Taiwan Military Conscripts. Inves Ophthalmol Vis Sci. 2013;54(2):1026-1233. 


\section{Publish your work in this journal}

Clinical Optometry is an international, peer-reviewed, open access journal publishing original research, basic science, clinical and epidemiological studies, reviews and evaluations on clinical optometry. All aspects of patient care are addressed within the journal as well as the practice of optometry including economic and business analyses. Basic and clinical

Submit your manuscript here: https://www.dovepress.com/clinical-optometry-journal research papers are published that cover all aspects of optics, refraction and its application to the theory and practice of optometry. The manuscript management system is completely online and includes a very quick and fair peer-review system, which is all easy to use. Visit http://www.dovepress. com/testimonials.php to read real quotes from published authors. 